\title{
Review on CPW - Fed Microstrip Antennas
}

\author{
Varsha Shah, PhD \\ Principal, \\ RCOE, Bandra, Mumbai - 50
}

\author{
Rajan Deshmukh \\ Head of Department, EXTC, \\ RCOE, Bandra, Mumbai - 50
}

\author{
Sudesh Agrawal, Junaid \\ Mandviwala, Roshni \\ Santani \\ Assistant Professor, EXTC, \\ RCOE, Bandra, Mumbai - 50
}

\begin{abstract}
A CPW-fed antenna with a semicircle placed on two rectangular patches for WLAN application and this antenna satisfies the frequency band $(5.15$ to $5.95 \mathrm{GHz})$ having return loss lower than $-10 \mathrm{~dB}$. A novel broadband design of a coplanar waveguide fed square slot antenna loaded with conducting strips is proposed and experimentally studied. A design of triangular wide slot antenna with same shaped patch which is fed by CPW and in this antenna patch is working as a radiating element and wide slot working as a ground. A wideband E-shaped microstrip patch antenna has been designed for high-speed wireless local area networks (IEEE 802.11a standard) and other wireless communication systems covering the 5.15- $5.825 \mathrm{GHz}$ frequency band. A dual band coplanar waveguide (CPW)-fed planar monopole antenna suitable for WLAN application is been presented. A CPW-fed antenna with a triangle placed on a rectangular patch with two semi circles placed on either sides for WLAN application and this Antenna satisfies the licensed frequency band (5.15 to $5.95 \mathrm{GHz}$ ) having return loss lower than $-10 \mathrm{~dB}$.
\end{abstract}

\section{Keywords}

Microstrip Antennas, Microstrip Patch Antennas, Wireless Communications

\section{INTRODUCTION}

Deschamps first proposed the concept of the MSA in 1953. However, practical antennas were developed by Munson and Howell in the 1970s. The numerous advantages of MSA, such as its low weight, small volume, and ease of fabrication using printed-circuit technology, led to the design of several configurations for various applications. With increasing requirements for personal and mobile communications, the demand for smaller and low-profile antennas has brought the MSA to the forefront [1].

An MSA in its simplest form consists of a radiating patch on one side of a dielectric substrate and a ground plane on the other side. The top and side views of a rectangular MSA (RMSA) are shown in Fig. 1. However, other shapes, such as the square, circular, triangular, semicircular, sectoral, and annular ring shapes shown in Fig. 2, are also used [1].

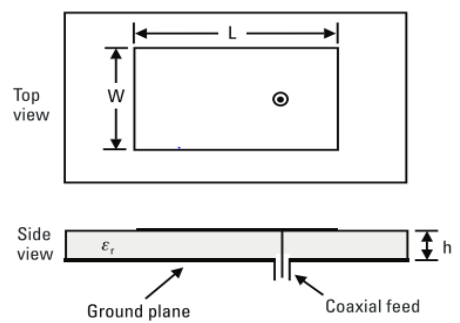

Fig.1 MSA Configuration
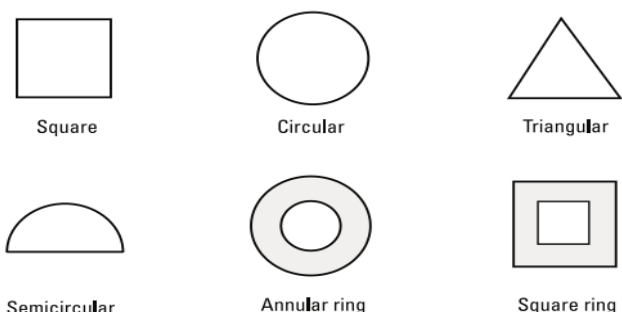

Semicircular

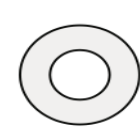

Annular ring

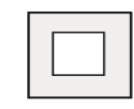

Square ring

Fig.2 Different shapes of microstrip patch antennas

Radiation from the MSA can occur from the fringing fields between the periphery of the patch and the ground plane. The length $L$ of the rectangular patch for the fundamental $\mathrm{TM}_{10}$ mode excitation is slightly smaller than $l / 2$, where $l$ is the wavelength in the dielectric medium, which in terms of freespace wavelength $l_{o}$ is given as $l_{o} l_{\sqrt{ }} e_{e}$, where $e_{e}$ is the effective dielectric constant of a microstrip line of width $W$. The value of $e_{e}$ is slightly less than the dielectric constant $e_{r}$ of the substrate because the fringing fields from the patch to the ground plane are not confined in the dielectric only, but are also spread in the air. To enhance the fringing fields from the patch, which account for the radiation, the width $W$ of the patch is increased. The fringing fields are also enhanced by decreasing the $e_{r}$ or by increasing the substrate thickness $h$. Therefore, unlike the microwave integrated circuit (MIC) applications, MSA uses microstrip patches with larger width and substrates with lower $e_{r}$ and thicker $h$. For MSA applications in the microwave frequency band, generally $h$ is taken greater than or equal to $1 / 16$ th of an inch $(0.159 \mathrm{~cm})$ [1].

\subsection{Dual-Band MSAs}

There is a considerable amount of interest in the development of a dual-band MSA because of its usefulness in various applications. These dual-band operations can be at fixed frequencies, or tunable at both or one of the frequencies. Fig. 3. depicts the VSWR plots for the fixed and tunable categories. The solid lines show two fixed frequencies, and the dotted lines show the tunability. Either both or one of the frequencies of dual-band operation could be tunable based on the application. Several MSA configurations for obtaining dual-band characteristics are discussed in this section [1]. 


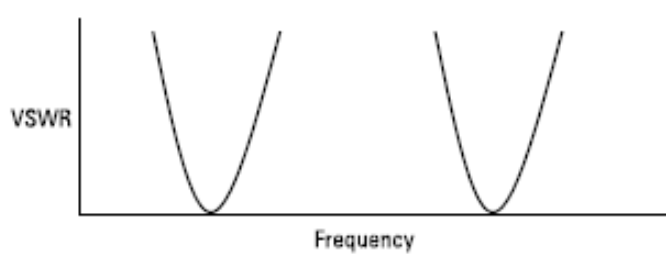

(a)

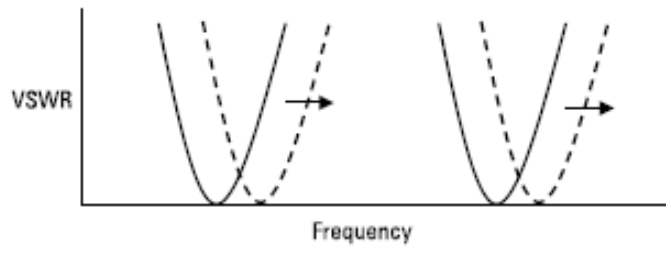

(b)

Fig.3 VSWR plots of two categories of dual-band operation: (a) fixed and (b) tunable.

\section{COMPACT CPW- FED ANTENNA WITH SEMICIRCLE ON TWO RECTANGULAR PATCHES FOR WLAN APPLICATION}

In the design of this type of antennas, the width ' $W$ ' and length ' $L$ ' play a crucial role in determining the resonant frequency of the system. The geometrical configuration of the proposed antenna is shown in Fig. 4. The parameters of the antenna are $\mathrm{L}=16.2, \mathrm{~W}=16.1, \mathrm{~L} 1=6, \mathrm{~L} 2=3, \mathrm{~L} 3=9, \mathrm{~L} 4=5$, $\mathrm{W} 1=6.3, \mathrm{~W} 2=6.1, \mathrm{~W} 3=1, \mathrm{R}=3.8, \mathrm{G}=2$ and substrate thickness $\mathrm{h}=1.2$.

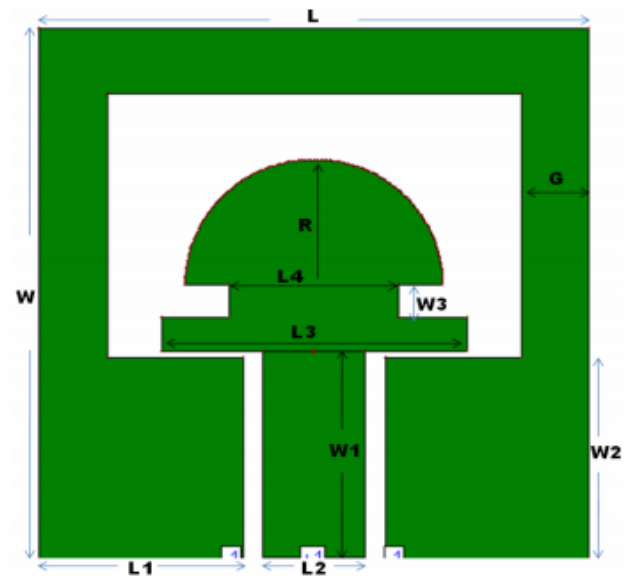

Fig.4 Layout of proposed antenna

A prototype of the novel compact CPW-fed Antenna with semicircle on two rectangular patches for WLAN band has been simulated. The simulated curve of return loss for the frequency range $4.89 \mathrm{GHz}$ to $6.41 \mathrm{GHz}$ is lower than $-10 \mathrm{~dB}$ and maximum return loss i.e. $-43 \mathrm{~dB}$ is observed at $5.31 \mathrm{GHz}$. The simulated voltage standing wave ratio (VSWR) of the antenna is less than 2 for frequency bands which covers the WLAN applications. Hence it is seen that at the resonant frequency [2].

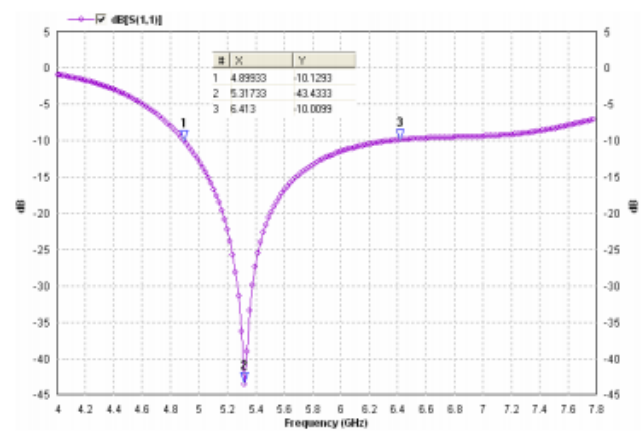

Fig.5 Proposed antennas return loss characteristic

Fig. 5 shows the simulated return loss characteristics with Elevation and azimuthal at a resonating frequency by using ZELAND IE3D software. The simulated radiation patterns of antenna in the E-plane (XZ-plane) and H-plane (YZ-plane) for $5.37 \mathrm{GHz}$. Advantages of this antenna are easy to construct, simple structure, and low cost. Good radiation characteristics for resonate frequency 5.31 has been obtained [2]

\section{A BROAD-BAND CPW-FED STRIP- LOADED SQUARE SLOT ANTENNA}

The proposed CPW-fed wide slot antenna is shown in Fig. 6. The proposed antenna has a single-layer metallic structure, and is printed on a dielectric substrate of thickness and relative permittivity $£$. The printed square slot has a side length of L. A $50 \mathrm{ohm}$ CPW, having a signal strip of thickness and a gap of distance between the signal strip and the coplanar ground plane, is used to capacitively excite the square slot. For achieving efficient excitation and good impedance matching, the signal strip of the CPW should be protruded into the square slot; the length of the protruded signal strip is denoted as $l_{2}$. Experimental results also show that the length $l_{2}$ of has a significant effect on the impedance bandwidth of a CPW capacitively coupled square slot antenna, the optimal length of is found to be about 0.45 to 0.61 times the slot's side length $l_{2}$. By further incorporating the loading of four metallic strips of the same dimensions protruded from the four corners of the square slot to the slot centre, it is found that a large impedance bandwidth can be obtained. From experiments, the optimal length of the metallic strips for band- width enhancement is determined to be about 0.6 to $0.81_{2}$ [3].

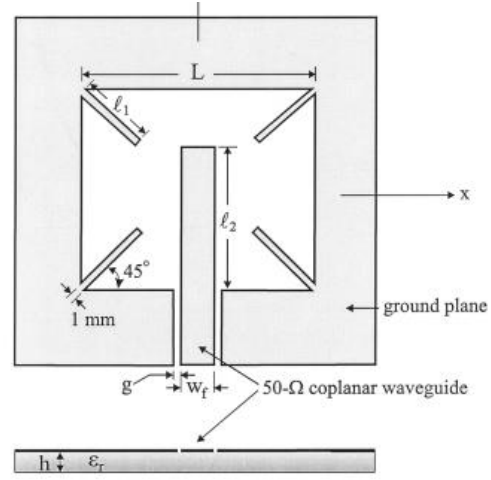

Fig.6 Geometry of the proposed CPW fed strip loaded square slot antenna 
TABLE 1: Performance of the propose antenna with a fixed tuning stub length $\left(l_{2}\right)$

\begin{tabular}{|l|l|l|l|l|}
\hline$l_{1}$ & $l_{2}$ & $l_{1} / l_{2}$ & fc MHz & $\begin{array}{l}\text { B.W } \\
\text { MHz, } \%\end{array}$ \\
\hline 0 & 24.5 & 0.00 & 1857 & $527,28.4$ \\
\hline 14 & 24.5 & 0.57 & 1849 & $618,33.4$ \\
\hline 16 & 24.5 & 0.65 & 2241 & $1410,62.9$ \\
\hline 18 & 24.5 & 0.73 & 2050 & $1101,53.7$ \\
\hline 19 & 24.5 & 0.78 & 1960 & $952,48.6$ \\
\hline 21 & 24.5 & 0.86 & 1801 & $641,35.6$ \\
\hline
\end{tabular}

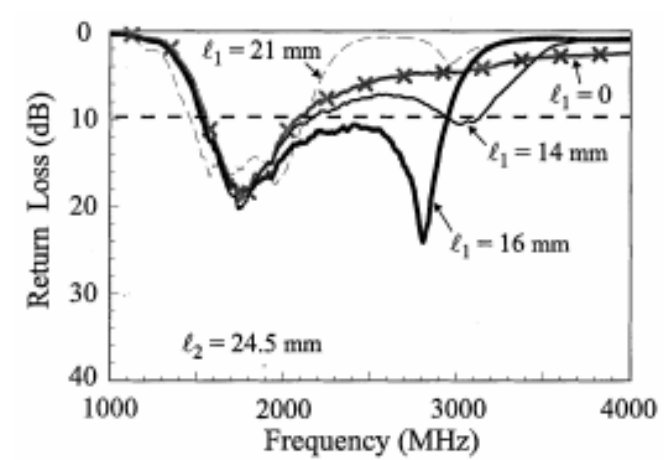

Fig.7 Measured return loss against frequency for the proposed antenna for a tuning stub length of $24.5 \mathrm{~mm}$

In the following experiments, the proposed bandwidth-enhancement technique of loading metallic strips at the slot corners is applied to the antenna with $l_{2}=24.5 \mathrm{~mm}$, which has a bandwidth comparable to the maximum bandwidth obtained for the case with $l_{1}=0$ in this study. Table I gives the antenna parameters and the measured center frequency and bandwidth for the constructed prototypes with various lengths of $l_{1}$. Measured results of the return loss against frequency for $l_{1}=0,14$, 16, and $21 \mathrm{~mm}$ are also presented in Fig. 7. It is clearly seen that owing to the presence of the loading strips, a new resonant mode is excited. When a proper length of the loading strips is selected, this new resonant mode can be shifted close to the antenna's fundamental resonant mode, resulting in a wide impedance bandwidth. From the results obtained, when is chosen such that is in the range of about 0.6 to 0.8 , a much enhanced impedance bandwidth is obtained. The maximum impedance bandwidth is as large as $1410 \mathrm{MHz}$ or about $62.9 \%$ centered at about $2.2 \mathrm{GHz}$, which is also about 2.0 times that of the antenna without the loading strips [3].

Broad-band operation of a CPW capacitively coupled square slot antenna with metallic strips loaded at the four slot corners has been demonstrated. The proposed antenna has a simple structure, and impedance matching can easily be achieved by tuning the lengths of the CPWs signal strip in the slot and the loading metallic strips. When a suitable length ratio of $1_{1} / l_{2}$ (about 0.6 to 0.8 , with $l_{2}$ about 0.45 to 0.61 times the slot's side length) is chosen, the impedance bandwidth of the proposed antenna can be significantly increased. Experimental results also show that with the optimal values of $l_{1}$ and $l_{2}$ chosen, the antenna's impedance bandwidth can be doubled, and an impedance bandwidth larger than $60 \%$ is obtained [3].

\section{COMPARATIVE STUDY, DESIGN AND PERFORMANCE ANALYSIS OF WIDE SLOT ANTENNA WITH PATCH-FEED FOR BANDWIDTH ENHANCEMENT}

The geometry of proposed antenna fabricated on the FR4 substrate with thickness of $0.8 \mathrm{~mm}$ and dielectric constant 4.4 as shown in Fig. 8. Antenna has a triangular-shape slot and an equilateral triangular-patch feed with an edge length of 15 $\mathrm{mm}$. The dimensions are given in $\mathrm{mm}$ in Table 2. Patch is working as a radiating element fed by CPW and wide slot working as a ground. By study of various papers three design rules are followed: Feed and slot shape should be similar. The widths and lengths for both feeds are about one third of the slot size. Lengths are close to but less than the quarter wavelength measured at the lower frequency edge. The lengths are shorter than a printed monopole at the same frequency, because the slot edge acts as a capacitive load to the monopole [4].

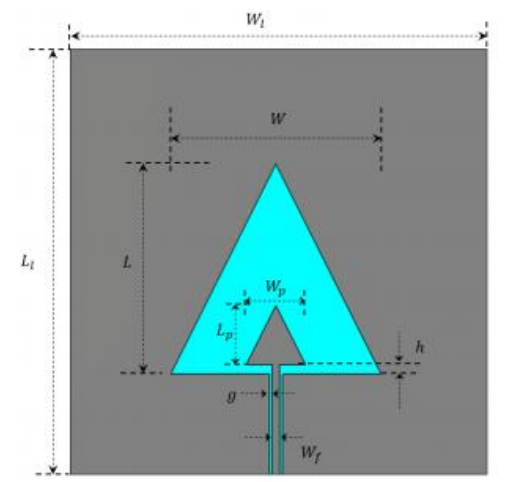

Fig.8 Geometry of proposed antenna

TABLE 2: All dimensions are in $\mathbf{m m}$

\begin{tabular}{|l|l|l|l|l|l|l|l|l|}
\hline Le & We & $\mathbf{L p}$ & $\begin{array}{l}\text { W } \\
\mathbf{p}\end{array}$ & $\mathbf{L}$ & $\mathbf{W}$ & $\begin{array}{l}\text { W } \\
\mathbf{f}\end{array}$ & $\mathbf{h}$ & $\mathbf{g}$ \\
\hline 110 & 110 & 15 & 15 & 52.7 & 52.7 & 2 & 2.5 & 0.75 \\
\hline
\end{tabular}

The center frequency is selected as the one at which the return loss is minimum. The bandwidth of the antenna is said to be those range of frequencies over which the return loss is greater than $7.3 \mathrm{~dB}$, Thus we measure required band at return loss $-10 \mathrm{~dB}$. From return loss plot given in Fig. 9, it is found that impedance band width is $116 \%$ and center frequency is 5 $\mathrm{GHz}[4]$.

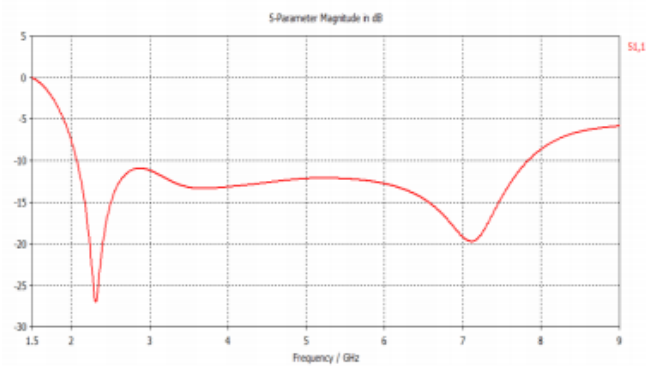

Fig.9 Return Loss Characteristics

A CPW feed wide slot antenna has been developed and 116\% bandwidth is achieved with stable radiation patterns across the 
whole band. It is found that the antenna feed and slot shapes should be similar for optimum impedance matching, but for better radiation patterns, a triangular shape slot should be used. In addition, the proposed antenna has small size, exhibit stable and almost omnidirectional radiation patterns in entire operating frequency band, relatively high gain and low cross polarization. Based on these findings the proposed antenna can be further improved for commercial purpose like WLAN, Wi-Fi, Wi- MAX, WTM [4].

\section{WIDEBAND E-SHAPED MICROSTRIP PATCH ANTENNA FOR 5-6 GHZ WIRELESS COMMUNICATIONS}

First, a rectangular microstrip patch antenna is designed based on the standard design procedure to determine the length (L) and width (W) for resonant frequency at $5.25 \mathrm{GHz}$. It is fed by a coaxial probe at position (xo, yo) as shown in Fig. 10. Two parallel slots are incorporated to perturb the surface current path, introducing local inductive effect that is responsible for the excitation of a second resonant mode. The slot length (Ls), slot width (Ws), and the center arm dimensions (Wt and $\mathrm{Lt}$ ) of the E-shaped patch control the frequency of the second resonant mode and the achievable bandwidth. By introducing a second resonant mode at around $5.8 \mathrm{GHz}$, the coupling of the two resonant modes may form a wide bandwidth response covering a bandwidth of 5.15-5.85 $\mathrm{GHz}$ [5].
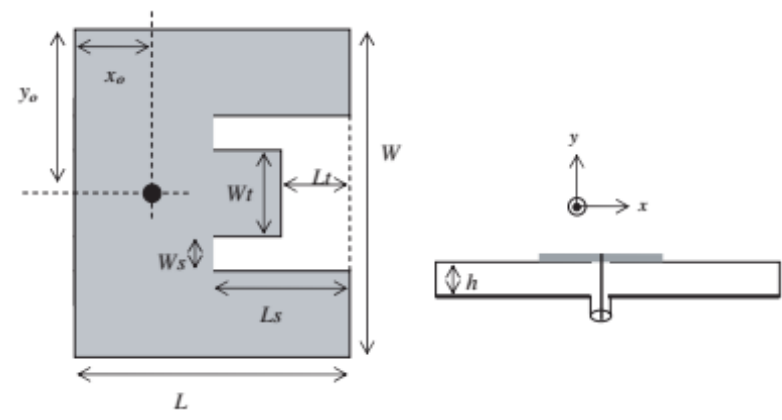

Fig.10 Configuration of $\mathbf{E}$ shaped microstrip antenna

A common rectangular patch antenna can be represented by means of the equivalent circuit. The resonant frequency is determined by $\mathrm{L}_{1} \mathrm{C}_{1}$. At the resonant frequency, the impedance of the series LC circuit is zero, and the antenna input impedance is given by resistance $R$. By varying the feed location, the value of resistance $\mathrm{R}$ may be controlled such that it matches the characteristic impedance of the coaxial feed. When a pair of slots is incorporated, the equivalent circuit can be modified. The second resonant frequency is determined by $\mathrm{L}_{2} \mathrm{C}_{2}$. Analysis of the antenna input impedance shows the three-dimensional perspective view of the printed meander lines. The width of metal patterns from 0.3 to $1.0 \mathrm{~mm}$ and the diameter of via holes is $0.5 \mathrm{~mm}$. A rectangular patch and a few E-shaped microstrip antennas are fabricated. Measurement results are obtained to compare with simulation results [5].

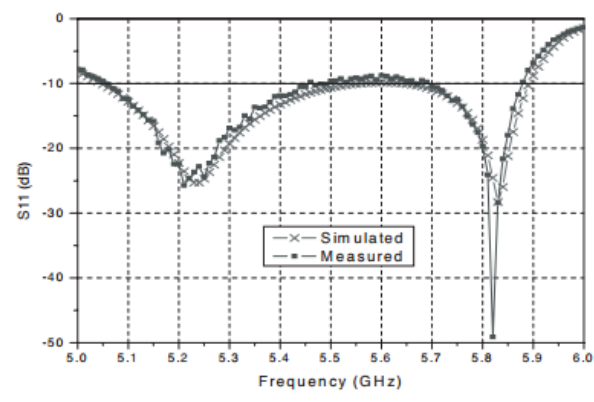

Fig.11 Simulated and measured reflection coefficients of an $E$ shaped microstrip antenna

In order to maintain a concise style of presentation, only one design example is reported in this paper. For a rectangular patch antenna, with dielectric constant of 2.2 and substrate thickness of $3.2 \mathrm{~mm}$, the typical bandwidth is about $400 \mathrm{MHz}$ (or $8 \%$ fractional bandwidth) at $5.25 \mathrm{GHz}$. Fig. 11 shows the measurement and simulation results for an E-shaped microstrip antenna with $\mathrm{Ls}=10 \mathrm{~mm}, \mathrm{Ws}=1.0 \mathrm{~mm}, \mathrm{Wt}=6$ $.2 \mathrm{~mm}$ and $\mathrm{Lt}=2.8 \mathrm{~mm}$. The design gives the widest bandwidth with reflection coefficient below $-10 \mathrm{~dB}$. A bandwidth of $830 \mathrm{MHz}$ (or $15.2 \%$ fractional bandwidth), covering $5.05 \mathrm{GHz}$ to $5.88 \mathrm{GHz}$, is achieved. The experimental results are in excellent agreement with the simulation results. The radiation patterns of the antenna are measured is as shown in Fig.12 [5].

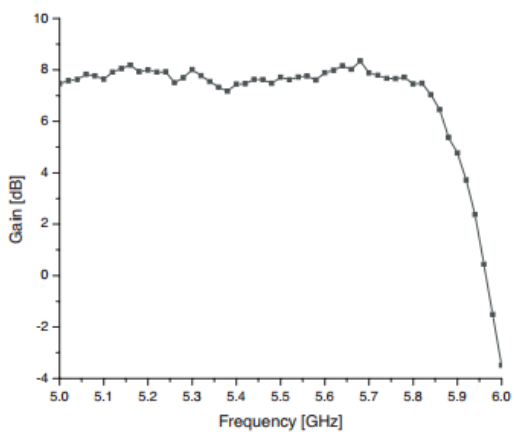

Fig.12 Measured radiation pattern gain of E-shaped antenna

Both the E-plane and H-plane have broadside directional radiation patterns similar to a common rectangular patch antenna. The radiation characteristic exhibits little variation at other frequencies over the $830-\mathrm{MHz}$ bandwidth. Fig. 10 shows the measured antenna gain is about $7.5 \mathrm{dBi}$ over the entire frequency range from $5.15 \mathrm{GHz}$ to $5.825 \mathrm{GHz}$, with ripple of less than $\pm 0.6 \mathrm{~dB}$. A wideband E-shaped microstrip patch antenna has been designed for high-speed wireless communication systems. The reflection coefficient is below $-10 \mathrm{~dB}$ from $5.05 \mathrm{GHz}$ to $5.88 \mathrm{GHz}$. The performance is more than meeting the demanding bandwidth specification to cover the $5.15-5.825 \mathrm{GHz}$ frequency band. At the same time, the antenna is thin and compact with the use of low dielectric constant substrate material. These features are very useful for worldwide portability of wireless communication equipment. The bandwidth can be easily tuned by trimming the length of the center arm [5]. 


\section{OPTIMAL DESIGN OF DUAL BAND CPW-FED G-SHAPED MONOPOLE ANTENNA FOR WLAN APPLICATION}

The geometrical configuration of the candidate CPW-fed planar monopole antenna for achieving dual band operation is shown in Fig. 13. For the proposed design here, the antenna is printed on only one side of an FR4 microwave substrate with the substrate thickness of $1.6 \mathrm{~mm}$ and the dielectric constant of 4.4. This construction is simpler than the presented dual band G-shaped antenna design which has a large ground plane on the side different from the G- shaped radiating patch. The main structure of the proposed antenna comprises two folded strips, denoted as L1 and L2, respectively, and a CPW feeding line. The strips L1 and L2 are both have a fixed strip width of $s$ and are folded to resemble the antenna in a "G" shape. For the smaller folded strip L1, it includes two horizontal sections. 1 for the lower and upper sections, respectively, and one vertical section of length of $(\mathrm{d} 1+\mathrm{s}+\mathrm{s})$ [6].

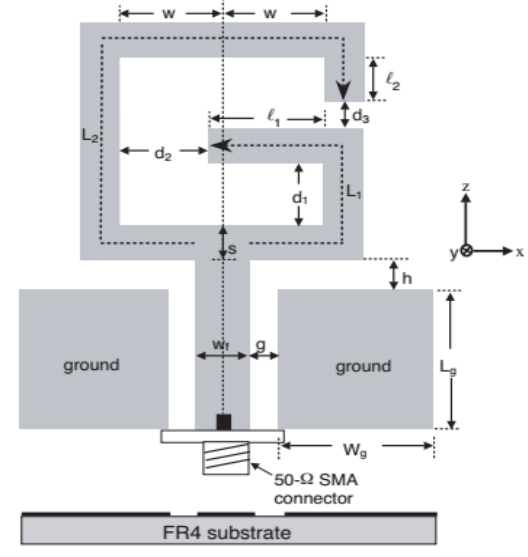

Fig.13 Geometrical configuration of a CPW-fed G shaped monopole antenna for dual band

As for the larger folded strip, L2, it includes two vertical and two horizontal sections, and can be determined by using only three parameters, which are the distances $\mathrm{d} 2$ and $\mathrm{d} 3 \mathrm{from}$ the upper horizontal section of the smaller folded strip to the left and right vertical section, of the larger folded strip, and the length 2 of the right vertical section of the larger folded strip. The major function of the two folded strips of unequal lengths is to produce two different current paths and thus expected to effectively excite dual resonant modes. A $50 \Omega$ CPW feeding line with a fixed signal strip thickness of wf and a gap distance of $g$ between the signal strip and ground is used for centrally feeding the G-shaped antenna from its bottom edge. Two equal finite ground planes, each with dimensions of width $\mathrm{Wg}$ and length $\mathrm{Lg}$, are situated symmetrically on each side of the CPW feeding line. The G-shaped radiating structure has a vertical spacing of $h$ away from the ground plane. In this investigation, for trying to obtain good dual band impedance matching by controlling the current distribution on the G-shaped strip line and compensation between the capacitive and inductive effects caused from the electromagnetic coupling effects of the finite ground planes and both the feeding line and the G- shaped strip line at the desired various operating bands, the geometry parameters of ( 1, 2, d1, d2, d3, s, wf, Wg, Lg, g, h) will be optimally selected by the PSO. Note that the value of length $w$ is determined by $(1+\mathrm{d} 2) / 2$, thus it is not included in the design variables for use in the PSO optimization procedure [6].
TABLE 3: Ranges of design parameters for the dual band CPW-fed G shaped monopole antenna (ranges are in mm)

\begin{tabular}{|l|l|l|l|l|l|l|l|l|l|l|}
\hline $\mathrm{l}_{1}$ & $\mathrm{l}_{2}$ & $\mathrm{~d}_{1}$ & $\mathrm{~d}_{2}$ & $\mathrm{~d} 3$ & wf & wg & Lg & $\mathrm{g}$ & $\mathrm{h}$ & $\mathrm{s}$ \\
\hline $\begin{array}{l}0- \\
15\end{array}$ & $\begin{array}{l}0- \\
15\end{array}$ & $\begin{array}{l}0- \\
15\end{array}$ & $\begin{array}{l}0- \\
15\end{array}$ & $\begin{array}{l}0- \\
15\end{array}$ & $2-5$ & $\begin{array}{l}5- \\
20\end{array}$ & $\begin{array}{l}5- \\
20\end{array}$ & $\begin{array}{l}0.2- \\
5\end{array}$ & $\begin{array}{l}0.2- \\
6\end{array}$ & $\begin{array}{l}1- \\
5\end{array}$ \\
\hline
\end{tabular}

Obviously, for the proposed design, varying the length of $l_{2}$, as expected, does not significantly change the lower resonant mode but does affect the impedance matching condition of the higher operating band. It should be note $\mathrm{l}_{2}=1.69 \mathrm{~mm}$, though the obtained return loss at $5.2 \mathrm{GHz}$ (about $-52.32 \mathrm{~dB}$ ) seems much higher than that in the optimized case (about $-37.33 \mathrm{~dB}$ ), the return loss at $2.45 \mathrm{GHz}$ in former case $(-28.71 \mathrm{~dB})$ is less than the later $(-30.13 \mathrm{~dB})$ to produce a less $l_{2}=1.19 \mathrm{~mm}$. In addition, we have also checked the case of decreasing the length of $\mathrm{L} 2$ to be $14.42 \mathrm{~mm}$, or about $0.25 \lambda$ with respect to the operating frequency at $5.2 \mathrm{GHz}$, and select the other parameters as the optimized design. The calculated result in Fig. 14 shows that the dual resonant modes do occur at 2.2 and $5.1 \mathrm{GHz}$. The two frequencies both have a frequency shift to the desired operating bands of 2.45 and $5.2 \mathrm{GHz}$, respectively. The shifts may mainly due to the electromagnetic coupling effects between the folded strips L1 and L2. In addition, it can also be found that the impedance matching at $5.2 \mathrm{GHz}$ band is much worse than that of the proposed optimal design. However, as the length of L2 increases from $0.25 \lambda$ to $0.9 \lambda$, the impedance bandwidth of the higher band is effectively increased. From these results, the dual-resonant modes for the proposed best- designed case can be concluded as that the lower operating mode is excited by the shorter folded-strip path L1 with an appropriate length of $0.25 \lambda$, while the higher broad operating band is occurred from the formed longer current path L2 with a length of $0.9 \lambda$, respecting to the resonant frequency of $5.2 \mathrm{GHz}[6]$.

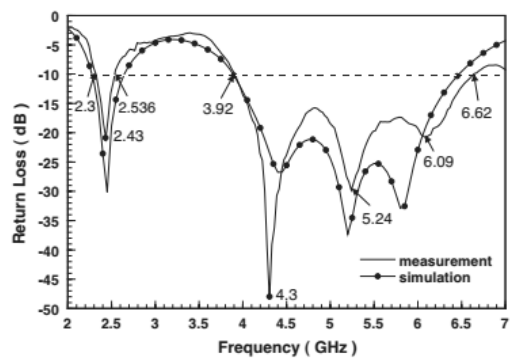

Fig.14 Return loss against frequency of proposed antenna from simulation and measurement: $11=10 \mathrm{~mm}$,

$2=1.19 \mathrm{~mm}, \mathrm{~d} 1=10 \mathrm{~mm}, \mathrm{~d} 2=3.32 \mathrm{~mm}, \mathrm{~d} 3=10 \mathrm{~mm}, \mathrm{~s}=$ $2.99 \mathrm{~mm}, \mathrm{wf}=4.75 \mathrm{~mm}, \mathrm{Wg}=5 \mathrm{~mm}, \mathrm{Lg}=10.75 \mathrm{~mm}, \mathrm{~g}=$ $1.35 \mathrm{~mm}$, and $\mathrm{h}=4.69 \mathrm{~mm}$

A novel CPW-fed G-shaped planar monopole antenna with dual band operation has been presented. The design process used the particle swarm optimization to optimize the performance of the antenna by choosing the most appropriate configuration parameters. In addition to demonstrate in detail the application of the PSO optimization technique to this antenna design, constructed prototype of the PSO-resulted antenna with dual impedance bandwidths of $9.7 \%$ and $62.8 \%$ at bands of 2.43 and $4.3 \mathrm{GHz}$, respectively, sufficiently covering the bandwidth requirements of the WLAN system in the $2.4 / 5.2 / 5.8 \mathrm{GHz}$ standards, have also been studied. Good antenna performances have been obtained [6]. 


\section{COMPACT NOVEL CPW - FED ANTENNA FOR WLAN APPLICATION}

The geometrical configuration of the proposed antenna is shown in Fig. 15. The parameters of the antenna are $M=15.2$, $\mathrm{N}=15.6, \mathrm{Ll}=5.5, \mathrm{~L} 2=3, \mathrm{~L} 3=6, \mathrm{~L} 4=6.3, \mathrm{Wl}=7, \mathrm{~W} 2=2.2, \mathrm{~W} 3=2$, $\mathrm{W} 4=1, \mathrm{~S}=5, \mathrm{r}=1, \mathrm{G}=1.5$ and $\mathrm{g}=\mathrm{O} .6$ Its simple structure is based on a one-layer FR4 dielectric substrate only, which has thickness as $h$ and permittivity of 4.4[7]. The Antenna size is $\mathrm{Mx} \mathrm{Lxh}$, in this paper we simulated the design with $\mathrm{h}=\mathrm{lmm}$.

The simulation results show that this antenna works for WLAN. The whole antenna structure is symmetrical about the y-axis in Fig. 15, based on systematic comparative studies by means of simulation using Method of Moment (MoM) from IE3D software. A set of suitable geometric parameters for the antenna is designed, and then checked and adjusted by experimental test [7].

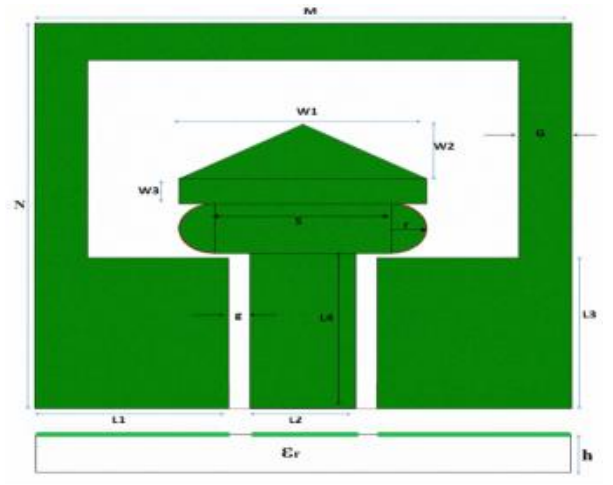

Fig.15 Design of Proposed Antenna

The proposed antenna is analyzed using IE3D and hence obtained WLAN application for $\mathrm{h}$ value. The Return Loss Characteristics of the antenna for $\mathrm{h}=\mathrm{lmm}$ has been observed. Hence, we obtain a band width of $18.62 \%$ from $5 \mathrm{GHz}$ to $6 \mathrm{GHz}$ with $-48 \mathrm{~dB}$ return loss which is applicable for WLAN application. Hence the return loss curve for this antenna has been plotted in Fig. 16. It is clear that the simulated voltage standing wave ratio (VSWR) of the wireless LAN aperture antenna is less than 2 for entire frequency range of 5 to $6 \mathrm{GHz}$ [7].

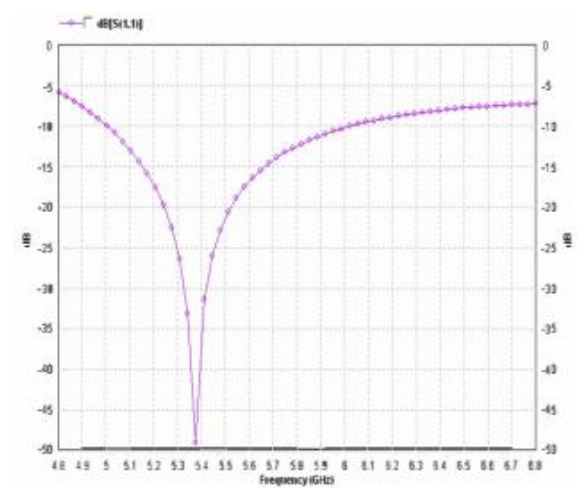

Fig.16 Return loss characteristics of antenna

The proposed antenna performed well over the WLAN frequencies $(5.1 \mathrm{GHz}-5.9 \mathrm{GHz})$. The proposed antenna has a compact dimension of $15.2 \times 15.6 \times 1 \mathrm{~mm}$. Advantages of this antenna are easy to construct, simple structure, and low cost. Good radiation characteristics for resonate frequency 5.37 has been obtained. The fundamental parameters of the antenna such as return loss, VSWR, gain, directivity are obtained. All meets the acceptable antenna standard and the satisfactory results are observed [7].

\section{CONCLUSION}

The CPW-Fed antenna provides a wide bandwidth depending upon its structure. Almost every band from $1 \mathrm{GHz}$ to $20 \mathrm{GHz}$ can be covered by the use of CPW-Fed antennas. However, a problem of less gain exists in these antennas. This problem can be fixed by increasing the area of the antenna or by using metamaterial substances. The antenna can be designed very easily and the current distribution decides the mode of the current and thus factors in the resonating modes. Various length of radiating patch and ground plane can be used to result in different length of the current and thus allowing different modes to excite themselves.

\section{REFERENCES}

[1] Antenna Theory, Analysis and Design by Constantine A. Balanis

[2] S. R. Hussain, S. Kareemulla and D. S. Kumar, "Compact CPW- fed antenna with semicircle on two rectangular patches for WLAN application," 2010 XVth International Seminar/Workshop on Direct and Inverse Problems of Electromagnetic and Acoustic Wave Theory (DIPED), Tbilisi, 2010, pp. 144-149.

[3] Jyh-Ying Chiou, Jia-Yi Sze and Kin-Lu Wong, "A broad-band CPW-fed strip-loaded square slot antenna," in IEEE Transactions on Antennas and Propagation, vol. 51, no. 4, pp. 719-721, April 2003.

[4] Jain, Pragya, and Sunil Kumar Singh. "Comparative Study, Design and Performance Analysis of Wide Slot Antenna with Patch-Feed for Bandwidth Enhancement."

[5] B.-K. Ang and B.-K. Chung, "A wideband e-shaped microstrip patch antenna for $5-6 \mathrm{GHz}$ wireless communications," Progress In Electromagnetics Research, Vol. 75, 397-407, 2007.

[6] W.-C. Liu, "Optimal design of dualband CPW-fed gshaped monopole antenna for WLAN application," Progress In Electromagnetics Research, Vol. 74, 21-38, 2007.

[7] M. Suresh Kumar, D. Sriram Kumar And I. Balakrishna, "Compact Novel Cpw- Fed Antenna For WLAN Application," 2010 International Conference On Communication Control And Computing Technologies, Ramanathapuram, 2010, Pp. 1-4. 